\title{
Competências Profissionais e o Processo de Formação na Residência Multiprofissional em Saúde da Família
}

\section{Professional Competences and the Training Process in a Multi-Professional Internship in Family Health}

\author{
Débora Dupas Gonçalves do Nascimento \\ Mestre em Enfermagem em Saúde Coletiva. Assessora Técnica da \\ Atenção Primária à Saúde Santa Marcelina e Preceptora da Resi- \\ dência Multiprofissional em Saúde da Família (Ministério da Saúde/ \\ Casa de Saúde Santa Marcelina/Faculdade Santa Marcelina). \\ Endereço: Rua Tuiuti, n 589, apt 224, bloco 4, Tatuapé, CEP 0308ı- \\ ooo, São Paulo, SP, Brasil. \\ E-mail: ddupasळuol.com.br \\ Maria Amélia de Campos Oliveira \\ Professora Titular do Departamento de Enfermagem em Saúde Co- \\ letiva da Escola de Enfermagem da Universidade de São Paulo. \\ Endereço: Av. Dr. Enéas de Carvalho Aguiar, n 419, Cerqueira César, \\ CEP 05403-000, São Paulo, SP, Brasil. \\ E-mail: macamposळusp.br
}

\section{Resumo}

A Residência Multiprofissional em Saúde da Família (RMSF) é uma modalidade de pós-graduação lato sensu cuja finalidade é desenvolver competências dos profissionais de saúde para o trabalho no SUS. Este estudo teve como objetivo construir um perfil de competências para orientar a formação profissional na RMSF. Pesquisa qualitativa realizada com 15 preceptores de uma RMSF e oito trabalhadores da Estratégia Saúde da Família. Para análise dos dados empíricos, utilizou-se a técnica de análise de discurso proposta por Fiorin (1999) e adaptada por Car e Bertolozzi. As competências encontradas foram classificadas nas áreas de domínio propostas por Witt: valores profissionais, comunicação, trabalho em equipe, gerência, orientada à comunidade, promoção da saúde, resolução de problemas, atenção à saúde, educacional e em ciências básicas da saúde pública e coletiva. A construção do perfil de competências revelou a potencialidade pedagógica e política da RMSF para transformação das práticas de cuidado em saúde e a necessidade de pensar a formação a partir de uma perspectiva ampliada do processo saúde-doença.

Palavras-chave: Competência profissional; Residência; Programa Saúde da Família; SUS. 


\section{Abstract}

Multi-professional internship in Family Health (MIFH) is a modality of a postgraduate degree specialization course, which is intended to develop competences in health professionals to work in SUS (Brazil's National Health System). Our objective was to construct a profile of competences to guide the professional training at MIFH. This qualitative research was performed with 15 preceptors of an MIFH and eight health workers of the Family Health Strategy. Empirical data analysis was conducted utilizing the discourse analysis techniques proposed by Fiorin and adapted by Car and Bertolozzi. The competences found were classified in the domain areas proposed by Witt: professional values, communication, teamwork, management, community oriented, health promotion, problem solving, attention to health, educational, and in basic sciences of public health. The construction of a competence profile revealed a pedagogical and political potentiality of the MIFH to transform health care practices and the need to consider education in a broader perspective of the health-disease process.

Keywords: Professional Competence; Internship; Family Health Program; SUS - Brazilian National Health System.

\section{A Residência Multiprofissional em Saúde da Família como Estratégia de Formação para o SUS}

Propostas de mudanças na formação em saúde no Brasil vêm sendo discutidas desde o final da década de 1980, com a proposição do Sistema Único de Saúde (SUS). Atualmente, essa discussão ganhou especial relevância quando o Ministério da Saúde (MS) chamou para si a responsabilidade de orientar a formação dos profissionais da saúde para atender as necessidades do SUS.

Ao apoiar a implantação das Diretrizes Curriculares Nacionais (DCN) para os cursos da área da saúde, o MS vem incentivando a formação profissional com vistas ao desenvolvimento de competências. Projetos como Pró-Saúde e PET Saúde sinalizam a ação indutora do Ministério para promover mudanças na formação inicial em saúde, por meio da aproximação das instituições formadoras dos serviços de saúde. Na modalidade de pós-graduação lato sensu, o MS apóia a Residência Multiprofissional em Saúde da Família (RMSF) por sua potencialidade para a formação do novo trabalhador em saúde.

A RMSF foi idealizada a partir da expansão da Estratégia Saúde da Família (ESF), que tem como alvo a reorganização da Atenção Básica e que, desde 1994, ainda com a denominação de Programa Saúde da Família, propõe um novo modelo assistencial para o SUS, centrado na atenção primária e na promoção da saúde familiar, assim como na mudança da ênfase individual para a coletiva e familiar e da ação curativa e reabilitadora para a promotora da saúde.

A RMSF tem como objetivo articular os conhecimentos adquiridos na formação inicial, muitas vezes fragmentados e desarticulados, com a complexidade dos determinantes que se inter-relacionam na vida e no cuidado à saúde da população. Foi inspirada na experiência da Residência Médica, a mais antiga modalidade de formação em serviço existente no País (Feuerwerker, 1998).

Apresenta-se como uma alternativa para promover a mudança da prática assistencial em saúde, capaz de favorecer o trabalho em equipe, as trocas efetivas de saberes e práticas e a construção de uma nova realidade de saúde para a população. Sua finalidade é preparar os profissionais de diversas 
áreas da saúde para trabalhar em equipe multidisciplinar na Estratégia Saúde da Família, com base nos princípios e diretrizes do SUS. Seu principal objetivo é direcionar a atuação dos profissionais de nível superior para atividades clínico-assistenciais aplicadas ao cuidado direto aos indivíduos e famílias em seu ambiente familiar e social (Gil, 2005).

De acordo com Nascimento e Quevedo (2008 p.48):

É a partir da vivência prática nos serviços, permeada por um suporte pedagógico específico e voltado para as necessidades da população, que se concretiza uma formação técnica e humanística, do profissional de saúde, uma vez que as situações-problema vivenciadas no cotidiano desses profissionais exigem ações que extrapolem o âmbito puramente científico/clínico.

A RMSF fundamenta-se na interdisciplinaridade como facilitadora da construção do conhecimento ampliado de saúde, em resposta ao desafio de atuar nas coletividades, visualizando as dimensões objetivas e subjetivas dos sujeitos do cuidado (Nunes, 2005). Busca não somente o crescimento profissional dos residentes, mas também promover a transformação do serviço de saúde que os recebe, incentivando a reflexão sobre a prática desenvolvida e as possibilidades e limites para transformá-la.

\section{As Competências na Formação em Saúde no Contexto da RMSF}

O conceito de competência vem sofrendo mudanças ao longo dos anos, passando de uma linha comportamentalista/behaviorista, fortemente utilizada na formação de técnicos, para uma abordagem dialógica em que se articulam tarefas e recursos cognitivos, afetivos e psicomotores.

Perrenoud (1999) define competência como a capacidade de agir eficazmente emdeterminada situação, apoiada em conhecimentos, mas sem se limitar a eles. Para o autor, a competência busca responder às necessidades do mundo contemporâneo; constrói-se na formação, mas também nas diferentes situações do trabalho.

Na área de educação, predominam três concepções de competência: a) combinação de atributos pessoais mobilizados em contextos específicos para atingir determinados resultados; b) coleção de atributos ou capacidades pessoais e c) relação de resultados observados ou esperados (Lima, 2004).

Para desenvolvê-las, há necessidade de uma construção curricular que possibilite o desenvolvimento de um perfil profissional em que habilidades e conteúdos se articulem com o contexto da prática profissional (Moraes, 2003).

Segundo Oliveira (2004), competências sugerem encontrar, identificar e mobilizar conhecimentos que darão subsídios para resolução dos problemas. Expressam-se na ação profissional, na relação com o outro, no dia-a-dia do trabalho (Witt, 2005).

Nas DCN da área da saúde, o perfil profissional faz referência ao generalista, com visão humanista, crítica e integradora, capaz de atuar com qualidade e resolubilidade no SUS. Os profissionais de saúde devem possuir competências para responder a necessidades e demandas de saúde da população em situações concretas.

A RMSF, que se caracteriza como um processo de formação a partir da inserção no trabalho, pode contribuir para o desenvolvimento dessas competências. Para isso, precisa estabelecer um perfil de competências voltado para o mundo do trabalho, que contemple as necessidades de saúde da população e que contribua para a consolidação do SUS.

Este estudo teve como objetivo construir um perfil de competências para orientar a formação profissional na RMSF; identificar a concepção de competência que orienta a prática pedagógica de preceptores de um programa de RMSF e as competências profissionais referidas por trabalhadores das equipes da ESF como necessárias no cotidiano de sua prática profissional.

\section{Metodologia}

Trata-se de um estudo de caso que adotou como categoria conceitual e analítica a competência, tal como definida por Perrenoud (1999). Ancora-se na formulação de Mendes-Gonçalves (1992) sobre o trabalho em saúde e de Peduzzi (2001), sobre o trabalho em equipe. Dentre os diversos tipos de trabalho, Mendes-Gonçalves (1992, p.1) salienta que "um dos mais notáveis é o trabalho em saúde”, pois tem como 
objeto o ser humano e contribui para a construção de uma visão dinâmica e objetiva da realidade, sendo uma ferramenta importante para transformá-la.

Para Peduzzi (2001), o trabalho em equipe multiprofissional é um tipo de trabalho coletivo em que ocorre uma interação recíproca entre as diversas intervenções e sujeitos por meio da comunicação e da cooperação em situações objetivas de trabalho. Essa integração pressupõe um “agir comunicativo", técnico e ético.

\section{Local do estudo}

O estudo foi desenvolvido no Programa de Residência Multiprofissional em Saúde da Família da Casa de Saúde Santa Marcelina/Faculdade Santa Marcelina/ Ministério da Saúde. O primeiro Programa de RMSF na instituição teve início em 2003 e, em 2009, formou sua terceira turma.

\section{População e amostra}

A população foi constituída por preceptores que atuam na RMSF e profissionais de saúde que integram equipes de ESF dos serviços que recebem os residentes.

Concordaram em participar do estudo todos os 15 preceptores envolvidos na residência, sendo três enfermeiros, um psicólogo, dois terapeutas ocupacionais, dois cirurgiões-dentistas, um fonoaudiólogo, três médicos, um nutricionista, um farmacêutico e um assistente social, identificados pela letra "P"e numerados de 1 a 15 . Solicitou-se a esses preceptores que indicassem profissionais das equipes da ESF, de reconhecida competência profissional, o que resultou em oito nomes: dois enfermeiros, um cirurgião-dentista, dois fonoaudiólogos e três médicos, identificados por "PI" e numerados de 1 a 8 .

A proposta de investigação foi submetida ao Comitê de Ética e Pesquisa da Escola de Enfermagem da Universidade de São Paulo e aprovada sob o $\mathrm{n}^{0}$ 635/2007/CEP/EEUSP. Seguindo as recomendações da Resolução nº 196/96 do Conselho Nacional de Pesquisa em Saúde, todos os 23 sujeitos convidados a participar do estudo foram esclarecidos dos objetivos da pesquisa e manifestaram sua concordância em participar por meio da assinatura do Termo de Consentimento Livre Esclarecido.

\section{Coleta e análise dos dados}

Os dados foram coletados por meio de entrevista individual semiestruturada, no período de agosto a dezembro de 2007. 0 material empírico resultante da transcrição das entrevistas foi submetido à técnica de análise de discurso preconizada por Fiorin (1999) e adaptada por Car e Bertolozzi (1999).

A primeira etapa consistiu na identificação de figuras e temas a partir das falas dos sujeitos. As figuras são os termos utilizados que remetem a algo do mundo concreto e natural, enquanto os temas estão relacionados aos significados abstratos. Posteriormente, buscou-se a articulação entre figuras e temas e, em seguida, foi realizada a recomposição dos discursos por meio de frases temáticas.

A análise dos discursos sintetizados em frases temáticas possibilitou o agrupamento e a categorização do material empírico de acordo com os quatro pilares da educação: saber conhecer, saber fazer, saber ser e saber conviver (Delors, 2003).

0 agrupamento dos temas resultou nas categorias empíricas do estudo. Em seguida, à luz do referencial teórico, procedeu-se à recomposição desses conhecimentos, habilidades e atitudes em competências, classificadas nas áreas de domínio propostas por Witt (2005). Vale ressaltar que esse modelo teórico adotado não foi tomado como lista exaustiva de competências, mas como recurso para o agrupamento do material empírico de forma coerente e compreensível.

\section{Resultados}

O movimento analítico e sintético que incidiu sobre o material empírico propiciou a construção de um quadro-síntese das competências por área de domínio, resultado de um processo de articulação dos discursos dos dois grupos entrevistados e que explicita as competências multiprofissionais desejáveis aos envolvidos no cenário da ESF.

O perfil de competência apresentado a seguir baseia-se, portanto, nas percepções de preceptores e profissionais do serviço sobre os atributos necessários à formação na modalidade RMSF e consequente atuação no contexto da Estratégia Saúde da Família. 
É importante salientar que essas competências desenvolvem-se e são incorporadas ao processo de formação a partir da vivência cotidiana nos serviços de saúde, ou seja, no mundo do trabalho.

\section{Quadro I - Síntese das competências para formação e atuação multiprofissional na Estratégia Saúde da Família por área de domínio. São Paulo, 2008}

\begin{tabular}{|c|c|}
\hline Área de Domínio & Competências \\
\hline $\begin{array}{l}\text { I. Valores } \\
\text { profissionais }\end{array}$ & $\begin{array}{l}\text { - Identificar-se com o programa (ESF) e desenvolver prática diferenciada com afinidade e engajamento pelo } \\
\text { trabalho } \\
\text { - Ter postura profissional resiliente, humanista, responsável, interessada, comprometida, envolvida, flexível, } \\
\text { humilde, compromissada, dinâmica, empreendedora e pró-ativa } \\
\text { - Trabalhar com atenção, respeito, vontade, interesse, espírito inovador, autonomia, otimismo e paciência, } \\
\text { de forma horizontal } \\
\text { - Trabalhar com dinamismo, iniciativa e disponibilidade }\end{array}$ \\
\hline 2. Comunicação & $\begin{array}{l}\text { - Saber ouvir com empatia, respeito e valorização do interlocutor } \\
\text { - Respeitar as diferenças e estabelecer diálogo } \\
\text { - Ter habilidade para abordar o usuário } \\
\text { - Dominar as tecnologias leves e ter habilidade nas relações interpessoais }\end{array}$ \\
\hline $\begin{array}{l}\text { 3. Trabalho } \\
\text { em equipe }\end{array}$ & $\begin{array}{l}\text { - Trabalhar em equipe, discutir casos e o plano de cuidados } \\
\text { - Reconhecer o saber dos profissionais da equipe e valorizar seus conhecimentos e opiniões } \\
\text { - Estar aberto para "trocar" com outros profissionais e para agregar pessoas } \\
\text { - Exercer liderança, sem autoritarismo }\end{array}$ \\
\hline 4. Gerência & $\begin{array}{l}\text { - Ter conhecimento sobre gestão e gerenciamento de recursos } \\
\text { - Ser capaz de construir um plano de ação/realizar um planejamento estratégico } \\
\text { - Saber planejar e organizar o trabalho a partir da incidência e prevalência de casos }\end{array}$ \\
\hline $\begin{array}{l}\text { 5. Orientada à } \\
\text { comunidade }\end{array}$ & $\begin{array}{l}\text { - Conhecer o território (área de abrangência e influência) e envolver-se com a comunidade. } \\
\text { - Trabalhar com grupos (terapêuticos e educativos) } \\
\text { - Ter olhar ampliado para família, compreender seu contexto de vida e trabalho } \\
\text { - Estimular a participação popular e o envolvimento no Conselho gestor } \\
\text { - Valorizar o indivíduo como pessoa em seu contexto (sua constituição e história) e como parte integrante de } \\
\text { um grupo social } \\
\text { - Vislumbrar possibilidades de ação a partir de um olhar abrangente sobre as necessidades dos indivíduos e } \\
\text { dos grupos sociais } \\
\text { - Respeitar o usuário, seu conhecimento e posicionamento diante do projeto terapêutico }\end{array}$ \\
\hline $\begin{array}{l}\text { 6. Promoção da } \\
\text { saúde }\end{array}$ & $\begin{array}{l}\text { - Saber conhecer e saber fazer promoção e educação em saúde } \\
\text { - Promover a autonomia, a participação e o respeito próprio dos usuários, favorecendo o desenvolvimento da } \\
\text { cidadania }\end{array}$ \\
\hline $\begin{array}{l}\text { 7. Resolução de } \\
\text { problemas }\end{array}$ & $\begin{array}{l}\text { - Ter habilidade para enfrentar e conduzir desafios e/ou problemas cotidianos } \\
\text { - Buscar parcerias intersetoriais } \\
\text { - Trabalhar com recursos, equipamentos e instrumentos disponíveis, desenvolvendo a criatividade } \\
\text { - Ser capaz de se adaptar ao trabalho e resolver problemas } \\
\text { - Desenvolver todo potencial na prática e a segurança no fazer para resolução dos problemas e efetividade } \\
\text { das ações }\end{array}$ \\
\hline 8. Atenção à saúde & $\begin{array}{l}\text { - Ter conhecimento para realizar consulta, fazer diagnóstico, prescrever e encaminhar para outros níveis de } \\
\text { atenção à saúde } \\
\text { - Ter visão de saúde integral, humanista e ampliada do processo saúde-doença (do social, familiar, da } \\
\text { economia, política e educação) } \\
\text { - Reconhecer que o enfoque clínico é insuficiente para o cuidado, necessitando também de envolvimento. } \\
\text { - Reconhecer-se como agente de saúde e fonte de recursos para comunidade } \\
\text { - Desenvolver ações de promoção, prevenção, assistência e reabilitação } \\
\text { - Transmitir confiança e ter postura aberta, sensível, acolhedora, atenciosa, afetuosa, facilitadora e } \\
\text { interessada pelo paciente e seus problemas }\end{array}$ \\
\hline
\end{tabular}




\section{Quadro I - Síntese das competências para formação e atuação multiprofissional na Estratégia Saúde da Família por área de domínio. São Paulo, 2008 (continuação)}

\begin{tabular}{|l|l|}
\hline Área de Domínio & Competências \\
& $\begin{array}{l}\text { - Reconhecer as limitações do saber e da ação profissionais, aprendendo com os erros do dia-a-dia e } \\
\text { buscando atualização, informação e instrumentalização permanentes } \\
\text { - Reconhecer que a Educação Permanente deve acontecer no dia-a-dia: na reunião de equipe, na supervisão, } \\
\text { na visita } \\
\text { - Reconhecer o trabalho como lócus de produção de saber } \\
\text { - Reconhecer que a teoria respalda a prática e que ambas se correlacionam problematizando a realidade } \\
\text { - Reconhecer que a aquisição de conhecimentos é permanente e que também se adquire nas relações } \\
\text { familiares, profissionais e na prática }\end{array}$ \\
\hline $\begin{array}{l}\text { I0. Em Ciências } \\
\text { Básicas da Saúde } \\
\text { Pública/Saúde } \\
\text { Coletiva }\end{array}$ & $\begin{array}{l}\text { - Ter formação generalista } \\
\text { - Ter conhecimento e habilidade técnica/clínica adquiridos na formação específica } \\
\text { epidemiologia, } \\
\text { - indicadores de saúde, práticas de saúde coletiva, rede de referência e contrareferência, princípios e } \\
\text { estratégias organizacionais da ESF }\end{array}$ \\
\hline
\end{tabular}

\section{Discussão}

\section{Valores profissionais}

São processos socioculturais e históricos que englobam a ética como norteadora da ação profissional, o comprometimento e o compromisso com a saúde individual e coletiva e a responsabilização pela atenção à saúde dos indivíduos (Witt, 2005).

Os achados deste estudo acerca desses valores indicam que, além da capacidade técnica, os profissionais que compõem as equipes de saúde da família precisam identificar-se e envolver-se com o modelo de trabalho, que exige criatividade, iniciativa, e vocação para o trabalho em grupo e com a comunidade, no que são corroborados por Ronzani e Silva (2008).

Esses mesmos autores afirmam que a ESF requer dos profissionais atributos como atenção, comprometimento e sensibilidade. No entanto, orientações capazes de produzir impacto na saúde e na qualidade de vida da população ainda são pouco valorizadas.

A fala de um dos profissionais indicados revela a importância do envolvimento do profissional para o desenvolvimento do trabalho na ESF:

Eu acho que não é só a questão técnica, ela é importante, é óbvio, mas eu acho que não éo maior diferencial, não. Ele pode ser muito competente numa área e não saber lidar com essa competência técnica. Eu acho que tem de ter esse envolvi- mento. Só que eu acho difícil ter esse envolvimento se você não gostar, não consegue. (PI6)

Somente o trabalho de respeito, atenção, responsabilidade e compromisso contínuos para com os usuários pode ser capaz de estreitar vínculos e garantir cuidados efetivos, integrais e emancipatórios, a partir da subjetividade, sensibilidade e engajamento social de profissionais e usuários dos serviços.

Gomes e Pinheiro (2005, p.295) consideram que:

[...] o desempenho do processo de trabalho do PSF deve estar relacionado à existência de profissionais que têm claro em suas mentes o papel de agente transformador, assegurando a participação e o controle social, tornando transparentes as informações, criando vínculos efetivos entre usuários e equipe e estabelecendo relações de trocas e confiança.

\section{Comunicação}

Em seu estudo, Witt (2005) refere-se à comunicação como uma ferramenta imprescindível para os profissionais da Atenção Básica, para promover as relações interpessoais com a equipe e com os usuários e para garantir a qualidade do cuidado.

A habilidade de se comunicar é indispensável ao profissional da saúde no desenvolvimento do trabalho em equipe na ESF e também para a interação adequada com o paciente no processo de cuidado. 
A comunicação nos relacionamentos interpessoais é fundamental para compartilhar conhecimentos entre os profissionais e entre estes e os usuários dos serviços de saúde.

O discurso abaixo evidencia o respeito para com o usuário como um componente fundamental no processo de comunicação:

A questão de respeitar o usuário, respeitar o conhecimento popular, respeitar o conhecimento de outras categorias, valorizar isso e, principalmente, a questão das relações. Cultivar a relação, tanto a relação profissional com outras categorias, na mesma categoria, como a relação com o usuário. (P1).

Respeitar as diferenças também aparece como competência relacionada ao cotidiano do trabalho em equipe, no qual o diálogo deve permear o desenvolvimento do trabalho, por meio do estabelecimento de um canal de comunicação e de uma prática comunicativa (Araújo e Rocha, 2007).

Reconhecendo a interação entre sujeitos e o saber popular como construtores de relações sociais, Stotz (2005) propõe a escuta da população e o diálogo com ela como quesitos indispensáveis para práticas de saúde, fundamentais, portanto, para a organização dos serviços da Atenção Básica.

No cotidiano do trabalho em saúde, respeitar as diferenças, estabelecer diálogo e ter habilidade para abordar o usuário são competências essenciais aos profissionais da saúde, pois com elas é possível construir vínculos na interação profissional-usuário, ampliando as possibilidades de cuidado e a adesão ao tratamento.

\section{Trabalho em equipe}

0 trabalho em equipe acontece no contexto das situações objetivas das práticas em saúde e consiste de uma modalidade de trabalho coletivo, mediado pela comunicação, que se estrutura nas relações recíprocas entre as várias intervenções técnicas e a interação dos diferentes profissionais e suas áreas específicas (Peduzzi, 1998).

É uma diretriz importante para a reorganização do processo de trabalho na ESF, tendo em vista as múltiplas e complexas necessidades da população. Somente o trabalho interdisciplinar, com foco na integralidade da atenção e na resolubilidade das ações em saúde, é capaz de fazer frente aos determinantes e condicionantes do processo saúde-doença vivenciados pelos indivíduos, famílias e grupos sociais.

A interação da equipe por meio de uma atuação contínua e envolvida pode contribuir de forma mais efetiva para as mudanças dos indicadores de saúde da população e, consequentemente, para a melhoria de sua qualidade de vida.

A competência para reconhecer o saber ser dos profissionais da equipe, valorizar seus conhecimentos e opiniões, estar aberto para "trocar" com outros profissionais e agregar pessoas é indispensável para o trabalho em equipe na lógica da ESF. Pressupõe maior integração entre os profissionais e as ações a serem desenvolvidas, por meio da socialização dos conhecimentos, em busca da interdisciplinaridade e da flexibilização das estratégias programadas, com a participação de todos os membros da equipe, sem hierarquias.

A dificuldade para trabalhar em equipe e o pouco preparo que lhe é dispensado na formação inicial são relatados no excerto a seguir:

[...] eu acho o que pega mais na Estratégia é a questão do trabalho em equipe, essa relação interpessoal que eu acho que é um desafio grande. Porque a gente é formado para trabalhar por nós mesmos, para nos sentirmos competentes. $\varepsilon$ trabalhar em equipe évocê, às vezes, depender do outro, é você respeitar o ritmo do outro. Eu acho que é aí que está o maior nó crítico para a gente $\left(\mathrm{P}_{3}\right)$.

Segundo Araújo e Rocha (2007), os profissionais da saúde não podem ficar prisioneiros de seu campo específico de saberes e práticas, limitando o processo de trabalho à aplicação das estruturas rígidas do conhecimento técnico-estruturado. A articulação dos saberes por meio de uma interação comunicativa e horizontal é um requisito indispensável no cotidiano do trabalho em equipe.

\section{Gerência}

Witt (2005) considera que para atuar na Atenção Básica, os profissionais da saúde devem desenvolver habilidades e atitudes gerenciais dirigidas à administração de recursos físicos, materiais e de informação, assim como para gerenciar as ações de saúde e o cuidado a indivíduos, famílias e coletividades. 
Segundo essa autora, cada profissional deve incumbir-se da gestão e da gerência dos serviços de saúde e da integração da equipe durante o planejamento e avaliação das ações.

0 discurso a seguir traz um exemplo relativo ao gerenciamento do tempo, do trabalho e dos recursos disponíveis:

[...] você se perde se não tiver a capacidade geral de organização, de planejamento. Porque isso, eu acho, que é o que diferencia mais qualquer profissional. Porque, por exemplo, eu tenho de saber que eu tenho uma agenda que é limitada e que eu sou um recurso para aquela comunidade, mas um recurso limitado. Como eu posso ser mais útil? Como vou gerenciar meu tempo? $\varepsilon$ eu só vou gerenciar de uma forma competente se eu entender, se conhecer aquela comunidade. Então, tem de ter uma capacidade de organização, por exemplo, para saber oque émais prevalente, qual é a maior incidência e como eu vou gastar a minha energia para poder ser mais efetivo (PI1).

A lógica da gestão engloba a integração entre os processos de gestão de pessoas, estratégias e organização, orientada por uma perspectiva mais horizontal e participativa, integrando todos os envolvidos no processo de trabalho. No entanto, a gerência frequentemente é assumida "sem a necessária autonomia para implementação das atividades gestoras, submetidas a interesses relacionados, prioritariamente, com a ordem econômica" (Pierantoni e col., 2006, p. 28).

Nessa área de domínio, Feuerwerker (2005, p.503) julga ser preciso enfrentar alguns desafios como "a ampliação da produção de conhecimento a respeito das estratégias de gestão democrática, do processo de trabalho em saúde, das diferentes possibilidades de construção da rede de atenção à saúde e que se produzam novas tecnologias de cuidado orientado às necessidades de saúde dos usuários”.

\section{Orientada à comunidade}

Starfield (2002) considera que somente um enfoque baseado na coletividade permite compreender o modo como a enfermidade se distribui entre os distintos grupos sociais. Em sua proposta de Atenção Primária, defende uma abordagem do processo saúde-doença a partir de parâmetros epidemiológicos e clínicos, utilizados de forma complementar, de modo a adequar os programas de atendimento às necessidades específicas de saúde de dada população.

O envolvimento dos serviços de saúde com essas necessidades deve partir do reconhecimento das especificidades locorregionais, da valorização do indivíduo como pessoa em seu contexto e como parte integrante de um grupo social:

Para mim é saber ouvir e ganhar esse paciente para perto de mim, mas como ser humano; gostar do que eu estou fazendo e ver ele como pessoa; ele está aqui precisando de mim, mas eu preciso entender em que contexto, em que território ele vive para poder atuar de acordo com o que eu aprendi na técnica, na minha teoria, para que eu possa por em prática, mas vendo o território em que ele vive ( $\left.\mathrm{PI}_{5}\right)$.

A territorialização gera a responsabilidade sanitária, ou seja, o comprometimento do serviço com os resultados da atenção à saúde oferecida na qualidade de vida de indivíduos, famílias e grupos destinatários do cuidado.

Embora o cuidado na ESF deva ser realizado por meio de estratégias individuais e grupais, o desenvolvimento de competências para trabalhar com grupos precisa ser estimulado como alternativa de superação das formas de exclusão, com vistas à justiça e cidadania, tendo como princípios norteadores o respeito às diferenças, a empatia e o vínculo (Chiesa e col., 2007).

A abordagem grupal na dinâmica de trabalho da ESF apresenta-se com objetivos diversificados, de acordo com cada profissional e com a realidade e necessidade locorregional, mas com foco na garantia de maior envolvimento e comprometimento da população, tendo em vista as questões que afetam à saúde dos indivíduos. Essa estratégia ainda não é utilizada com frequência pelos profissionais nos serviços de saúde, assim como a abordagem familiar e, quando ocorre, muitas vezes tem o enfoque curativo e individualizado.

\section{Promoção da saúde}

A promoção da saúde é fundada em uma concepção ampliada do processo saúde-doença e seus determinantes, que articula saberes técnicos e populares. Compreende o incentivo e o apoio a ações comuni- 
tárias e a elaboração de programas para minimizar riscos e agravos à saúde; a articulação intersetorial para efetivar ações de promoção da saúde; as medidas de controle ambiental; a socialização de informações para o fortalecimento da saúde e da vida em todos os contextos sociais (domicílio, escola, trabalho, comunidade) e estreitamento dos vínculos intersetoriais e com a comunidade em prol da promoção da saúde e da saúde como um direito de todos (Ruiz, 2001).

No contexto da ESF, ações de promoção da saúde fazem parte do enfoque de reorientação do modelo assistencial. Nessa perspectiva, a educação em saúde deixa de ser considerada uma simples estratégia para a prevenção de doenças para se tornar um instrumento de conscientização e de superação de vulnerabilidades.

A educação em saúde é um dos principais elementos da promoção da saúde. Pautada numa perspectiva emancipatória, adota o diálogo participativo como base de sustentação e está baseada em "práticas de saúde desenvolvidas no 'território da vida' - e que inclui a pluralidade de saberes e práticas de lidar com problemas de saúde” (Stotz, 2005, p. 9).

o empowerment ou "empoderamento" é um conceito que advém da promoção da saúde e que, incorporado pelos profissionais nas práticas educativas, individuais e coletivas, visa garantir aos usuários dos serviços de saúde a autonomia para fazer escolhas conscientes e consistentes a partir da informação e da conscientização sobre a saúde como qualidade de vida. Pressupõe compreender, compartilhar e incentivar ações de promoção da saúde a partir do entendimento da própria saúde com suas "determinações sociais, econômicas, políticas e culturais mais amplas do que simplesmente a herança genética, a biologia humana e os fatores ambientais mais imediatos" (Buss, 2003, p. 36).

Nessa perspectiva, uma competência desejável aos profissionais da ESF relaciona-se ao estímulo da autonomia por meio do cuidado:

o cuidado é a busca da autonomia. Então, se eu tenho conhecimento que eu adquiri, eu vou aplicar esse conhecimento na busca da autonomia daquela pessoa que eu estou assistindo, que eu estou cuidando, né? Fornecendo a ela... instrumentos e habilidades para que ela consiga tocar a sua vida sozinha, independente do grau de complexidade da assistência. Se eu estivesse no hospital, seria de um jeito, se eu estivesse na Atenção Básica, de outro (PI7).

Para Leite e Vasconcelos (2006), a cultura e a vivência dos indivíduos fornecem elementos para a compreensão e incorporação das práticas de saúde. Para isso, os profissionais da saúde precisam organizar as informações disponíveis de modo que elas façam sentido para a vida de cada pessoa.

\section{Resolução de problemas}

A resolução de problemas é outra competência geral dos profissionais de saúde, definida como a capacidade de identificar e compreender a dimensão individual e coletiva dos problemas de saúde, priorizando os casos urgentes com resolubilidade e iniciativa (Witt, 2005).

Uma formação voltada para o mundo do trabalho, tal como preconizada pela RMSF, deve preparar o profissional de saúde para a identificação das necessidades de saúde dos grupos sociais, assim como para proposição de respostas efetivas aos seus problemas de saúde. Enfrentar esses problemas no cotidiano do trabalho na ESF é um grande desafio, tendo em vista seus determinantes e condicionantes, que extrapolam o setor saúde. Quando se considera que as vulnerabilidades ao adoecimento e a morte resultam das formas de produção e reprodução social, é indispensável buscar parcerias intersetoriais.

É necessário ao profissional da ESF ter habilidade para enfrentar e conduzir desafios e/ou problemas no dia-a-dia do trabalho:

\section{[...] o que espero de um profissional na estratégia} não é que ele vá resolver todos os problemas, porque a gente não vai conseguir mesmo, mas que ele saiba lidar com esses problemas e que seja facilitador para que outras pessoas se apropriem dessa realidade, principalmente a população $\left(\mathrm{P}_{3}\right)$.

A Atenção Básica utiliza predominantemente tecnologias leves no processo de cuidar. É desejável que o profissional da saúde saiba trabalhar com os recursos, equipamentos e instrumentos disponíveis, desenvolvendo a criatividade, incentivando e subsidiando os indivíduos a cuidarem de si, da família 
e da coletividade, objetivando sua autonomia e a emancipação (Machado e col., 2007).

\section{Atenção à saúde}

Essa área de domínio está relacionada ao saber/fazer dos profissionais, voltada para o desenvolvimento de ações individuais e coletivas, em âmbito integral e contínuo, por meio de ações de promoção, proteção, assistência e reabilitação.

Segundo Witt (2005), a atuação profissional ainda é fortemente centrada na clínica e o enfoque biológico permanece hegemônico, em detrimento das dimensões social e da subjetividade, contribuindo para que as ações de promoção da saúde e prevenção de agravos fiquem em segundo plano.

A atuação clínica com enfoque na doença, na prescrição e no tratamento é de fundamental importância no contexto do cuidado à saúde, uma vez que a população brasileira encontra-se adoecida. Entretanto, deve estar associada a uma visão ampliada de saúde, que incorpore ao fazer profissional competências que lhe possibilitem uma visão humanista e integral do processo saúde-doença, nos aspectos político, econômico, educacional, familiar, dentre outros.

Silva e Sena (2008) consideram que a formação profissional não pode ter como referência apenas a doença, mas deve estimular uma compreensão ampliada das necessidades de saúde, com vistas à integralidade do cuidado, incluindo o acolhimento e a escuta ampliada como indispensáveis para atenção à saúde, como exemplifica o trecho: "[...] principalmente pela questão do acolhimento, da escuta e do cuidado, porque eu acho que são as principais... os principais pontos para você trabalhar dentro do Programa Saúde da Família (P6)".

A Atenção Básica, como uma das portas de entrada do Sistema de Saúde, requer a responsabilização dos profissionais pelas ações desenvolvidas, com consequente aumento da resolubilidade. Tendo em vista a dificuldade dos serviços da Atenção Básica para realizar a referência do usuário para outro nível de atenção e a pouca utilização de tecnologias leve-duras ou duras, muitas vezes o recurso de saúde mais efetivo na UBS é o próprio profissional.

Diante dessa situação, na ESF, o profissional precisa reconhecer-se como agente promotor de saúde e fon- te de recursos para comunidade, agindo no máximo de sua capacidade resolutiva.

\section{Educacional}

A formação profissional exige aperfeiçoamento contínuo por meio da busca permanente de conhecimentos e da identificação de espaços de aprendizagem possibilitados pelo compartilhamento de saberes e experiências entre os profissionais. Reconhecer-se em contínua formação foi uma competência geral, identificada por Witt (2005) para todos os profissionais da saúde.

A Educação Permanente (EP) está vinculada à política de descentralização, que tem como base o desenvolvimento dos serviços de saúde a partir de suas características e necessidades. A aprendizagem à luz da EP é reconstrutiva e envolve o repensar das práticas e a análise dos enfrentamentos, que não são constantes e padronizados. Requer dos profissionais e serviços disponibilidade para aprender e para modificar a ação, por meio do diagnóstico e do planejamento participativo, com vistas a transformar a realidade.

Para promover essa articulação, é preciso a participação da equipe de forma horizontal, capaz de compreender que as relações são produtos de práticas e saberes acumulados, delimitadas pela dinâmica da realidade social, mas que são passíveis de transformação a partir da incorporação de um novo saber advindo do trabalho em saúde (Brasil, 2005).

Segundo Pereira (2003, p. 1532) "aprender é um ato de conhecimento da realidade concreta”, ou seja, por meio da vivência prática, novos conceitos são incorporados tendo em vista uma aproximação crítica da realidade. Sendo assim, reconhecer que a teoria respalda a prática e que ambas se correlacionam problematizando a realidade, foi uma competência mencionada nessa área de domínio.

Reconhecer o trabalho como lócus de produção de saber também foi considerada uma competência para o trabalho em ESF, o que reforça as potencialidades da RMSF para a transformação dos saberes e das práticas em saúde:

Porque, às vezes, não é no falar que você vai entender,é no fazer mesmo. Eu acho que a maior parte das coisas que eu entendi como conhecimento nesse sentido do processo foi fazendo 
mesmo [...]. E aí, só vivendo mesmo, só fazendo. Eu não vejo muito outra alternativa (PI3)

De acordo com Silva e Sena (2008), o profissional competente é capaz de reordenar a relação trabalho-educação, fundamentada na práxis, de forma a potencializar as ações em saúde, reconhecendo a subjetividade dos indivíduos, seu contexto, assim como as questões éticas envolvidas no trabalho em saúde.

\section{Em Ciências Básicas da Saúde Pública/Saúde Coletiva}

Segundo Witt (2005), essa área de domínio possibilita uma compreensão ampliada das condições de saúde da população, seus determinantes e condicionantes, o que pode contribuir para promoção da saúde e a prevenção de agravos, interferindo na utilização dos serviços de saúde.

Para essa autora, as competências gerais em Ciências Básicas da Saúde Pública e Coletiva englobam conhecer a rede de serviços de saúde, o Sistema Nacional de Saúde e as políticas de saúde; demonstrar capacidade técnica e conhecimento dos problemas e das necessidades de saúde da população, incluindo seus determinantes sociais, e saber socializar seus conhecimentos.

Para viabilizar o modelo de atenção preconizado pelo SUS, é preciso que os profissionais desenvolvam uma visão generalista, capaz de enfrentar os desafios da Atenção Básica, em consonância com os princípios e diretrizes do SUS, tanto na formação inicial, como na residência ou em outras modalidades de pós-graduação.

A formação generalista implica adquirir conhecimentos para além da clínica, com foco também nas Ciências Sociais, um conhecimento teórico que possibilite a análise, a reflexão e a transformação da realidade e das práticas de saúde em determinados grupos sociais. Nesse sentido, ter formação generalista é uma das competências necessárias aos profissionais na ESF.

O desafio de uma formação generalista está na urgência em integrar as diversas disciplinas, saberes e práticas, tendo como foco o cuidado centrado no indivíduo, na família e na coletividade (Furtado, 2007). Também é indispensável ter conhecimentos e habilidades técnicas adquiridas na formação específica.

Os entrevistados consideraram que, para o desenvolvimento do trabalho na ESF, é imprescindível ao profissional ter conhecimento sobre políticas públicas, processo saúde-doença, atenção primária, interdisciplinaridade, epidemiologia, indicadores de saúde, práticas de saúde coletiva, rede de referência e contra-referência, princípios e estratégias organizacionais da ESF. Esses conhecimentos, uma vez articulado ao cenário das práticas, ou seja, à Atenção Básica, tornariam possível o enfoque generalista:

[...] além daquele conhecimento de formação, que você tem, que vem lá da sua... da questão acadêmica, que é fundamental, você precisa, lógico, conhecer os princípios da atenção primária, você precisa saber o que é integralidade, você precisa saber como operacionalizar a integralidade $(\mathrm{P} 1)$.

A RMSF necessita pensar a formação a partir de uma perspectiva ampliada do processo saúdedoença dos indivíduos, assim como refletir sobre as competências e ações que devem ser desenvolvidas por todos os profissionais no contexto da ESF, pois o enfoque técnico das práticas em saúde não possibilita comprovar o caráter social e a maneira característica de adoecer e morrer dos grupos humanos (Toledo e col., 2007).

\section{Considerações Finais}

A reorganização da Atenção Básica nos moldes da ESF requer a renovação das práticas de saúde, dos vínculos de compromisso e de co-responsabilidade entre os serviços de saúde e os usuários (Vasconcelos, 1999). Para ser capaz de reconhecer as necessidades da população, é preciso que o profissional compreenda que processos de adoecer são expressões das formas de vida e trabalho e saúde, determinadas socialmente e expressas na subjetividade, ou seja, nas percepções, crenças e valores dos indivíduos assistidos (Toledo e col., 2007).

Nas palavras de Leonello (2007, p.74), um dos desafios para os profissionais da saúde está no "exercício cotidiano de reconhecimento e respeito à autonomia das pessoas em relação ao seu modo de 
andar a vida, como forma de reafirmar o compromisso com a atenção à saúde integral e humanizada". O estabelecimento de vínculos entre profissionais e usuários e a participação nos conselhos de saúde constituem espaços de confiança e construção dessa autonomia na perspectiva dos preceptores e profissionais por eles indicados.

Para Oliveira (2004), a formação dos profissionais precisa estar pautada na reflexão e na criação de novas tecnologias de cuidado à saúde, incorporando a escuta aos processos singulares e subjetivos, o estabelecimento de relações de confiança e vínculo entre profissionais e usuários e o compromisso com a resolução de problemas do território.

A construção desse perfil de competências evidenciou a necessidade de pensar a formação na RMSF a partir de uma perspectiva ampliada do processo saúde-doença, assim como refletiu as competências desejáveis para os profissionais envolvidos no contexto da ESF, por meio da imersão pelo e no trabalho, oportunizada por esta estratégia.

Ainda que se refiram especificamente à RMSF, os achados desse estudo podem ser tomados como ponto de partida para outras investigações referentes aos perfis de competência em programas de residência por área profissional, objeto de editais recentes do Ministério da Saúde e Educação.

Sabe-se que a transformação da formação e das práticas é um desafio a ser superado em várias instâncias, pois implica mudanças de paradigmas já estruturados nos serviços, nas instituições de ensino e nas relações interpessoais. Apenas o diálogo e a aproximação das práticas e das concepções de atenção à saúde vigente tornarão possível construir um novo modo de trabalho em saúde, centrado no usuário, com qualidade, resolubilidade e equidade.

Como parte das estratégias de formação permanente para o SUS, a RMSF apresenta potencialidades pedagógicas e políticas para transformação do modelo de atenção e das práticas de cuidado em saúde a partir da aprendizagem vivenciada no contexto real do trabalho em saúde em Unidades de Saúde da Família.

\section{Referências}

ARAÚJO, M. B. S.; ROCHA, P. M. Trabalho em equipe: um desafio para a consolidação da estratégia de Saúde de Família, Ciência \& Saúde Coletiva, Rio de Janeiro, v. 12, n. 2, p. 455-64, mar.abr. 2007.

BRASIL. Ministério da Saúde. Secretaria de Gestão do Trabalho e da Educação na Saúde. Curso de formação de facilitadores de educação permanente em saúde: unidade de aprendizagem: práticas educativas no cotidiano do trabalho em saúde. Rio de Janeiro: Ministério da Saúde, 2005. $62 \mathrm{p}$.

BUSS, P. M. Uma introdução ao conceito de promoção da saúde. In: CZRESNIA, D.; FREITAS, C. M. (orgs.). Promoção da saúde: conceitos, reflexões, tendências. Rio de Janeiro: Editora Fiocruz, 2003. p.15-38.

CAR, M. R.; BERTOLOZZI, M. R. O procedimento da análise de discurso. In: CHIANCA, T. C. M.; ANTUNES, M. J. M. (orgs.). A Classificação Internacional das Práticas de Enfermagem em Saúde Coletiva: CIPESC. Brasília: ABEN, 1999. (Série Didática: Enfermagem no SUS). p. 348-53.

CHIESA, A. M. et al. A formação de profissionais da saúde: aprendizagem significativa à luz da promoção da saúde, Cogitare enfermagem, Curitiba, v. 12, n. 2, p. 236-40, abr.-jun. 2007.

DELORS, J.(org.). Educação: um tesouro a descobrir: relatório para a UNESCO da Comissão Internacional sobre Educação para o Século XXI. 8. ed. São Paulo: Cortez, 2003.

FEUERWERKER L. Modelos tecnoassistenciais, gestão e organização do trabalho em saúde: nada é indiferente no processo de luta para a consolidação do SUS. Interface: comunicação, saúde, educação, Botucatu, v. 9, n. 18, p. 489-5o6, set.-dez. 2005.

FEUERWERKER, L. C. M. Mudanças na educação médica e residência médica no Brasil. Interface: comunicação, saúde, educação, Botucatu, v. 2, n. 3 , p. 51-71, ago. 1998. 
FIORIN, J. L. Elementos de análise do discurso. 7. ed. São Paulo: Contexto, 1999.

FURTADO, J. P. Equipes de referência: arranjo institucional para potencializar a colaboração entre disciplinas e profissões. Interface: comunicação, saúde, educação, Botucatu, v. 11, n. 22, p. 239-255, maio-ago. 2007.

GIL, C. R. R. Formação de recursos humanos em saúde da família: paradoxos e perspectivas. Cadernos de Saúde Pública, Rio de Janeiro, v. 21, n. 2, p. 490-498, mar.-abr. 2005.

GOMES, M. C. P. A.; PINHEIRO, R. Acolhimento e vínculo: práticas de integralidade na gestão do cuidado em saúde em grandes centros urbanos. Interface: comunicação, saúde, educação, Botucatu, v. 9, n. 17, p. 287-302, mar.-ago. 2005.

LEITE, S. N.; VASCONCELOS, M. P. C. Negociando fronteiras entre culturas, doenças e tratamento no cotidiano familiar. História, ciências, saúde - Manguinhos, Rio de Janeiro, v. 13, n. 1, p. 113-28, jan.-mar. 2006.

LIMA, V. V. Avaliação de competência nos cursos médicos. In: MARINS, J. J. N. et al. (orgs.). Educação médica em transformação: instrumentos para a construção de novas realidades. São Paulo: Hucitec, 2004. p.123-40.

MACHADO, M. F. A. S. et al. Integralidade, formação de saúde, educação em saúde e as propostas do SUS: uma revisão conceitual. Ciência \& Saúde Coletiva, Rio de Janeiro, v. 12, n. 2, p. 33542, 2007.

MENDES-GONÇALVES, R. B. Práticas de saúde: processos de trabalho e necessidades. São Paulo: CEFOR, 1992. 53 p. (Cadernos CEFOR. Textos, 1).

MORAES, M. J. B. O ensino de enfermagem em saúde coletiva: redescobrindo caminhos para novas práticas assistenciais. 2003. Dissertação (Mestrado em Enfermagem) - Escola de Enfermagem da Universidade de São Paulo, Universidade de São Paulo, São Paulo, 2003.
NASCIMENTO, D. D. G.; QUEVEDO, M. P. Aprender fazendo: considerações sobre a Residência Multiprofissional em Saúde da Família na qualificação de profissionais da saúde. In: BOURGET, M. M. M. (org.). Estratégia Saúde da Família: a experiência da equipe de reabilitação. São Paulo: Martinari, 2008. p. 43-59.

NUNES, E. D. Pós-graduação em Saúde Coletiva no Brasil: histórico e perspectivas. Physis: Revista de Saúde Coletiva, Rio de Janeiro, v. 15, n. 1, p. 13-38, 2005 .

OLIVEIRA, M. A. C. Da intenção ao gesto: a dialética da formação de enfermagem em saúde coletiva. 2004. Tese (Livre -docência) - Escola de Enfermagem da Universidade de São Paulo, Universidade de São Paulo, São Paulo, 2004.

PEDUZZI, M. Equipe multiprofissional de saúde: a interface entre trabalho e interação. 1998. 254 f. Tese (Doutorado) - Faculdade de Ciências Médicas da Unicamp, Universidade Estadual de Campinas, Campinas, 1998.

PEDUZZI, M. Equipe multiprofissional de saúde: conceito e tipologia. Revista de Saúde Pública, São Paulo, v. 35, n. 1, p. 103-9, 2001.

PEREIRA, A. L. F. As tendências pedagógicas e a prática educativa nas ciências sociais. Cadernos de Saúde Pública, Rio de Janeiro, v. 19, n. 5, p.15271534, set.-out. 2003.

PERRENOUD, P. Construir as competências desde a escola. Porto Alegre: Artes Médicas Sul, 1999.

PIERANTONI, C. R.; VARELLA, T. C.; FRANÇA, T. Recursos humanos e gestão do trabalho em saúde: da teoria à prática. Cadernos RH Saúde, Brasília, v. 3, n. 1, p. 27-38, 2006.

RONZANI, T. M.; SILVA, C. M. O Programa Saúde da Família: segundo profissionais de saúde, gestores e usuários. Ciência \& Saúde Coletiva, Rio de Janeiro, v. 13, n. 1, p. 23-34, jan.-fev. 2008. 
RUIZ, L. De la realidada las disciplinas: estructuración de las respuestas educacionales con base en las competencias de las instituciones y de la fuerza de trabajo.In: Organización Panamericana de la Salud. División de Desarrollo de Sistemas y Servicios de Salud. Programa de Desarrollo de Recursos Humanos. Educación en salud pública: nuevas perspectivas para las Américas Washington D.C: Organización Panamericana de la Salud, 2001. p.134-159. Disponível em: <http://www.paho.org/Spanish/ HSP/HSR/competencias.doc $>$. Acesso em: 10 jan. 2008.

SILVA, K. L.; SENA, R. R. Integralidade do cuidado na saúde: indicações a partir da formação do enfermeiro. Revista da Escola de Enfermagem da USP, São Paulo, v. 42, n. 1, mar. 2008. Disponível em: <http://www.scielo.br/pdf/reeusp/v42n1/o7. pdf $>$. Acesso em: 04 abr. 2008.
STARFIELD, B. Atenção primária: equilíbrio entre necessidades de saúde, serviços e tecnologia. Brasília: UNESCO, 2002. 726 p.

STOTZ, E. N. Os desafios para o SUS e a educação popular: uma análise baseada na dialética da satisfação das necessidades de saúde. 2005. Disponível em: <http://www.edpopsaude.net/ edpopsaude/Pol\%C3\%ADticas_e_Sistemas_files/ Stotz\%20-\%20DesafioSUS.pdf $>$. Acesso em: 01 abr. 2005 .

WITT, R. R. Competências da enfermeira na atenção básica: contribuição à construção das funções essenciais de Saúde Pública. Tese (Doutorado em Enfermagem em Saúde Pública) - Escola de Enfermagem de Ribeirão Preto, Universidade de São Paulo, Ribeirão Preto, 2005.

Recebido em: 18/08/2009

Reapresentado em: 08/04/2010

Aprovado em: 19/04/2010 